\title{
AVALIAÇÃO DE PRODUTO DE USO COTIDIANO POR MEIO DE CRITÉRIOS DE USABILIDADE: espremedores de fruta
}

\author{
Jamille Noretza de Lima Lanutti \\ PPGDesig - UNESP \\ jamille_lanutti@hotmail.com \\ Luis Carlos Paschoarelli \\ PPGDesign - Unesp \\ paschoarelli@faac,unesp.br
}

\begin{abstract}
Resumo: A usabilidade tem ampliado seu escopo e trabalhos tem sido realizados relacionando-a a produtos de uso diário. Este artigo discute o uso e interação com um produto de uso doméstico, apresentando para isso avaliação de alguns critérios relacionados à usabilidade em espremedores de frutas cítricas de diferentes formatações estéticas e valores simbólicos, buscando identificar a influencia nas diferentes composições formais em alguns critérios da usabilidade, como a eficiência e a satisfação. Observando que os diferentes espremedores, apesar de serem objetos simples, permitem diferentes resultados que são também influenciados pelas percepções diversas. Participaram deste estudo 36 sujeitos adultos do sexo feminino.
\end{abstract}

Palavras-chave: design, usabilidade, doméstico, espremedor de frutas

\begin{abstract}
Usability expanded its scope and you work has been carried out relating it to everyday products. This article discusses the use and interaction with a product for domestic use, presenting it to evaluate some criteria related to usability in citrus squeezers different formats aesthetic and symbolic values, seeking to identify the influences on different formal compositions on some criteria of usability such as efficiency and satisfaction. Noting that different juicers, despite being simple objects allow different results are also influenced by different perceptions. Perticiparam this study 36 adult female subjects.
\end{abstract}

Keywords: design, usability, domestic fruit juicer 


\section{INTRODUÇÃO}

Produtos de uso doméstico tem sido cada vez mais valorizados e vêm sofrendo grandes transformações, não apenas nos materiais utilizados, mas também na composição formal. É bem verdade que muitas das mudanças objetivam facilitar uso, requerendo menos força, ou tornando a tarefa possível de ser realizada com maior rapidez e facilidade. No entanto, observa-se que, com tantos produtos similares no mercado, uma forma de diferenciá-los é o design.

No entanto, segundo Moraes (2001), muitos acidentes com produtos de consumo estão ligados ao mau design, e o problema se concentra principalmente nas deficiências do sistema homem-objeto. Como na falta de informações no produto sobre seus riscos e características, ou ainda na composição formal que buscando a diferenciação, acabam se tornando pouco intuitivas ou ineficientes.

Moraes (2005) afirma que qualquer consumidor com senso crítico consegue apontar erros de um produto que já está nas prateleiras. Entretanto, observam-se cada vez mais produtos que, possuindo um forte apelo estético-simbólico, acabam se tornando atrativos, sem grande preocupação com a usabilidade.

Dessa forma, mesmo produtos produzidos por empresas com tradição em projetos com "bom Design" acabam sendo apontados pelos usuários por apresentarem sérios problemas durante o uso. Isso provavelmente ocorra, pois quando um produto é familiar à maioria das pessoas, deduz-se que são simples de usar e acaba-se por não dar importância ao teste de usabilidade.

Destaca-se, neste sentido, que cabe ao Design Ergonômico a tarefa de antecipar a constatação destes problemas, bem como, minimizá-los ou eliminá-los. Ao que se pode afirmar que na maioria das vezes um problema de usabilidade só é possível de ser identificado durante o processo de interação com o produto. Contudo, profissionais da área da ergonomia podem analisar e prever que tipos de dificuldades podem surgir desta interação, a fim de garantir o design apropriado do produto. Afinal, métodos e técnicas da ergonomia avaliam as relações do produto com o usuário, e desta forma, ergonomistas podem intervir para que problemas sejam eliminados ou minimizados (HANCOCK et al., 2001).

Este artigo busca entender, mesmo em produtos ditos simples - espremedores de frutas cítricas com um único elemento e não elétricos -, a influencia das diferentes composições formais em alguns critérios da usabilidade, como eficácia, eficiência e satisfação.

\section{REFERENCIAL TEÓRICO}

\subsection{A usabilidade na avaliação de produtos}

De acordo com a Norma Brasileira - NBR 9241-11, "Usabilidade é a medida na qual um produto pode ser usado por usuários específicos para alcançar objetivos específicos com eficácia, eficiência e satisfação em um contexto específico de uso". Especificando ainda que as medidas de Eficácia estão "relacionadas aos objetivos do usuário quanto à precisão e a completude com que estes objetivos podem ser alcançados", ou seja, ocorre quando o usuário alcança o objetivo inicial da tarefa, é avaliado quanto à finalização da tarefa e qualidade do resultado obtido (ABNT, 2002, p. 6). Enquanto as medidas de Eficiência "relacionam o nível de eficácia alcançada ao dispêndio de recursos", ou seja, refere-se aos esforços e recursos necessários para 
chegar a um determinado objetivo, tais como: esforço mental ou físico, tempo, custos materiais ou financeiros (ABNT, 2002, p. 6). E a satisfação "mede a extensão pela qual os usuários estão livres de desconforto e suas atitudes em relação ao uso do produto" e pode ser especificada e medida pela avaliação subjetiva em escalas de desconforto experimentado, gosto pelo produto, satisfação com o uso do produto ou aceitação da carga de trabalho quando da realização de diferentes tarefas ou a extensão com os quais objetivos particulares de usabilidade foram alcançados. Sendo mais difícil de avaliar por ser subjetiva (ABNT, 2002, p. 6).

Em sua origem, o termo usabilidade foi cunhado para substituir a expressão "amigável ao usuário", que no início dos anos de 1980, acabou adquirindo conotações indesejavelmente vagas e subjetivas.

Já consolidado o termo, desde a metade da década de 1990, a comunidade de desenvolvimento de interfaces empregou métodos de usabilidade para projetar e testar softwares e sistemas quanto à facilidade do uso, à facilidade de aprendizagem, memorização, à isenção de erros e à satisfação do usuário (SANTA-ROSA; MORAES, 2012b, p. 16).

Assim, Han et al. (2001) em um estudo que buscou avaliar produtos eletrônico levantou discussões quanto ao uso do conceito de usabilidade, usado inicialmente em $\mathrm{HCl}$, para o projeto e avaliação de outros produtos. Desatando que "usabilidade consiste no grau em que os usuários são satisfeitos com o produto com respeito tanto à performance quanto à impressão subjetiva" (HAN et al., 2001, p. 149).

Moraes (2001) destacou a importância da adaptação dos produtos à tarefa, ao usuário e ao contexto de uso. Para a pesquisadora, a usabilidade refere-se à "[...] adequação entre o produto e as tarefas a cujo desempenho ele se destina, da adequação com o usuário que o utilizará e da adequação ao contexto em que será usado" (p.15). Aproximando assim o conceito do projeto de produto.

lida (2005) faz o mesmo ao destacar o uso do produto na definição que afirma que usabilidade (do inglês usability) significa "facilidade e comodidade no uso de produtos, tanto no ambiente doméstico como no profissional. Os produtos devem ser 'amigáveis', fáceis de entender, faces de operar e pouco sensíveis a erros". Além disso, para o autor "a usabilidade relaciona-se com o conforto, mas também com a eficiência dos produtos", e "a usabilidade não depende apenas das características do produto. Depende também do usuário, dos objetivos pretendidos e do ambiente em que o produto é usado". Destacando ainda que a usabilidade "depende da interação entre o produto, o usuário, a tarefa e o ambiente" (p.320).

Neste contexto, destaca-se o papel da Ergonomia, intimamente ligada a Usabilidade, pois visa proporcionar eficácia e eficiência, além de bem-estar e saúde do usuário, por meio da adaptação do trabalho ao homem. Isto significa que seu objetivo é "garantir que sistemas e dispositivos estejam adaptados à maneira como o usuário pensa, comporta-se e trabalha e, assim proporcionem usabilidade" (CYBIS, BETIOL e FAUST, 2010, p. 16).

Logo, pode-se afirmar que a Ergonomia é fundamental, e seus métodos, técnicas e procedimentos, indispensáveis para adequar a apresentação da composição formal de um produto ao modelo mental dos usuários. Além de auxiliar no entendimento de como os usuários compreendem os produtos, como suas experiências e expectativas influenciam suas estratégias durante a interação e como estas estratégias mudam com a prática. 
Destacando-se a importância deste tipo de abordagem para o Design, que busca a redução da carga mental e cognitiva do usuário e o aproveitamento dos modelos mentais relacionados à experiência do usuário. Assim, é possível concluir que desde o início da atividade projetual o uso de abordagens da Ergonomia - e da Usabilidade devem estar presentes (CHAMMAS e MORAES, 2007).

Para Moraes (2004 apud CHAMMAS e MORAES, 2007) a usabilidade é apenas parte das metodologias ergonômicas utilizadas para adequação das interfaces tecnológicas às características e capacidades humanas físicas, cognitivas e emocionais. No entanto, Kurosu e Kashimura (1995) afirmam que o uso dessas metodologias durante as primeiras etapas do processo de desenvolvimento do projeto de produto, leva o designer elaborar a interface baseado na aplicação de estratégias para melhorar a sua usabilidade inerente. Assim, quando o produto é lançado no mercado, ele atrai o usuário também por meio de sua usabilidade aparente, bem como pelo preço, função, tamanho, aspectos estéticos, etc.

Dumas e Redish (1999, apud Santa-Rosa, 2012, p. 147) destacam que a aplicação de testes de usabilidade é apropriado desde o pré-design (testar um produto similar ou uma versão mais antiga), no design inicial (testar protótipos) e no desenvolvimento (testar aspectos diferentes e retestar ações). Ou seja, podem e devem estar presente em diferentes etapas do projeto de desenvolvimento de produto.

Além disso, utilizando testes de usabilidade, o pesquisador pode verificar se os usuários entendem o design como se suporia que entendessem (SANTA-ROSA e MORAES, 2012a, p. 147).

\section{Objetivo}

Este estudo teve como objetivo realizar avaliações de alguns critérios relacionados à usabilidade durante o uso de equipamentos domésticos (espremedores de frutas cítricas), visando compreender a influencia dos diferentes desenhos de produto na eficiência e na satisfação da atividade.

\section{Materiais e métodos}

\subsection{Sujeitos}

A definição da amostragem baseou-se na teoria da inferência estatística, sendo definido um total de 36 sujeitos adultos, todos do sexo feminino, com idade média de 38,25 e dp.13,27.

\subsection{Objetos de estudo}

Com propósito de conseguir identificar as diferentes percepções entre objetos com características e percepções distintas, foram selecionados cinco modelos de espremedores manuais de frutas cítricas para fazer o processo de avaliação (figura 1). A escolha dos mesmos deu-se considerando a interação sujeito-objeto, ou seja, os espremedores selecionados são totalmente manuais e necessitam de uma base como suporte no momento de aplicação de força. 


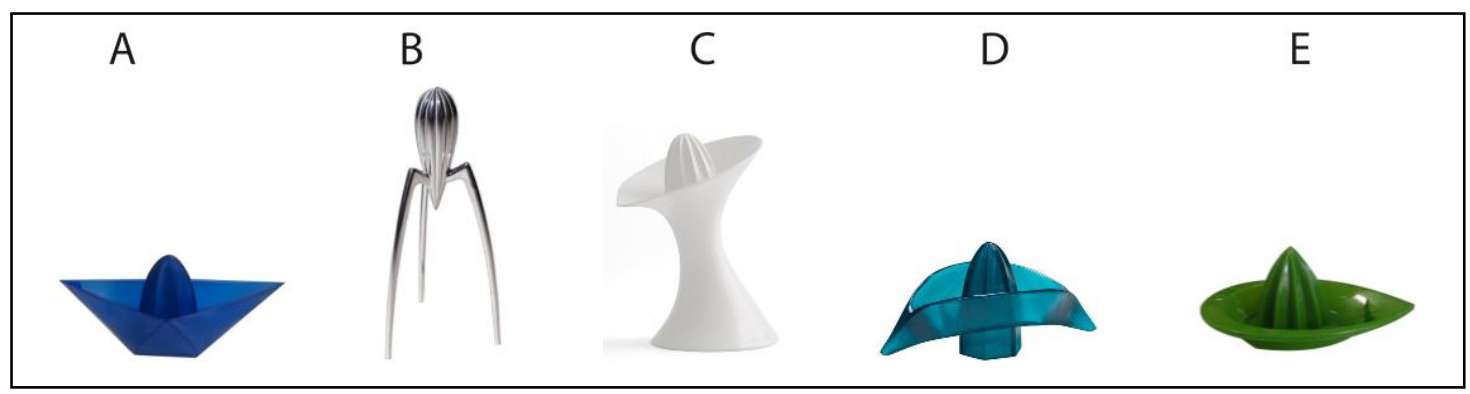

Figura 1 - Espremedores selecionados para avaliação (elaborado pelo autor).

O espremedor A é fabricado pela Koziol, empresa alemã que tem como objetivo criar objetos que se tornem ícones do design mundial e que tem a seguinte filosofia:

Uma escova é uma escova. Mas não se for da koziol, então não é uma escova, é arte. Não é o tipo de arte que junta a poeira em um canto ou fica trancada em um museu. Koziole é a ao alcance das mãos, a arte que sempre vai dar uma mãozinha. Ela irá limpar os legumes, servir sua salada e iluminar sua casa. Desde o início da koziol, criamos coisas que gostamos, coisas que tornam nossa vidas mais fáceis e mais felizes. Cada produto é uma prova visível e palpável da grande dedicação aos detalhes que colocamos em tudo o que é criado. Isto é arte de verdade. Isso é arte no trabalho (KOZIOL, 2013).

Desenhado pelo designer Paolo Pedrizetti em 1999, tem intencionalmente a forma baseada na popa de um barco. Inclusive seu nome, Ahoi, trata de uma saudação simbólica usada entre marinheiros alemães. Segundo a Koziol tem como diferencial as diversas cores nas quais é fabricado e o fato de ter poder ser usado em ambos os lados ao despejar o suco em outro recipientes, com dimensões $20 \times 9,5 \times 8,5 \mathrm{~cm}$.

$O$ espremedor $B$ de frutas fabricado pela Alessi, empresa italiana reconhecida por produzir ícones reconhecidos mundialmente, que tem como missão

A transformação da função de dispositivo atribuído aos objetos pela sociedade de consumo em uma oportunidade de transição, ou seja, em uma oportunidade para o consumidor melhorar sua percepção do mundo. [...] No futuro, a maioria dos nossos produtos continuarão a ser marcado por um alto grau de inovação e experimentação, pois acreditamos que este é o caminho para desenvolver a nossa capacidade de definir as tendências, promovendo a nossa fama e criando um meio de cultura que visa desenvolver projetos que gostamos de chamar Super populares (ALESSI, 2013).

Foi desenhado pelo designer Philippe Starck em 1990, e segundo a fabricante Alessi trata-se de um objeto verdadeiramente icônico e simbólico com sua forma surpreendente, tendo inclusive alvo de estudos (SILVA e OKIMOTO, 2011; e MORAES, 2001; LLOYD e SNELDERS, 2001). Inspirado na forma de uma lula, desenhado inicialmente no guardanapo de um restaurante a beira mar.

Tem como diferencial a forma inusitada, o fato de ser produzido em alumínio e a possibilidade de poder espremer a fruta diretamente no copo, com dimensões $14 \times 14$ X $29 \mathrm{~cm}$ Destaca-se ainda que foi projetado para limões sicilianos.

O espremedor C é fabricado pela Qualy, empresa tailandesa que tem como foco principal levar às pessoas que usam seus produtos um estilo de vida que reflita qualidade em todos os sentidos. "Os produtos Qualy são projetados para atender 
tanto a função quanto os fins decorativos. E todos os produtos e embalagens são $100 \%$ recicláveis" (QUALY, 2013).

Com projeto inspirado na natureza, sua parte superior tem a forma de uma folha e busca no movimento do orvalho ao pingar. Também é oferecido em diferentes cores e tem como diferencial o fato de poder espremer o suco diretamente no copo, devido suas dimensões: $23 \times 17 \times 16,5 \mathrm{~cm}$.

O espremedor de frutas $D$ é fabricado pela Ikko, empresa brasileira que tem como objetivo oferecer ao mercado.

\begin{abstract}
Ideias inteligentes com design marcante, que se transformam em utensílios singulares e funcionais, privilegiando toda a riqueza do nosso país em seus detalhes, sejam nas cores ou na alegria, são características internacionalmente reconhecidas como exclusividade cultural do Brasil (IKKO, 2013).
\end{abstract}

Desenhado pelo designer Luciano Deviá em 2005, tem a forma de um chapéu de cangaceiro, que segundo a empresa é um objeto típico do nordeste brasileiro, de seu folclore e sua cultura. Tendo como diferencial o material transparente (acrílico) e também as diversas cores nas quais é produzido, com dimensões $19 \times 10 \times 7 \mathrm{~cm}$.

E o espremedor E é fabricado pela Plasútil, principal empresa fabricante de utilidades domésticas em plásticos do Brasil, reconhecida pela produção de produtos com formas simples e que atendem a um publico alvo de variada condição socioeconômico (PLASUTIL, 2013).

Pode-se dizer que tem como diferencial o baixo preço pelo qual pode ser comprado e o fato de ser pequeno e fácil de guardar, com dimensões $15 \times 9,2 \times 6 \mathrm{~cm}$.

\title{
4.3 Materiais
}

Neste estudo realizou-se o uso simulado dos espremedores de frutas cítricas. No qual, desejando que os limões tivessem um tamanho padrão, realizou-se a compra de limões - do tipo tahiti - nos mercados e supermercados, que foram devidamente medidos com ajuda de um paquímetro, procurando padronizar um tamanho médio a ser seguido. Dessa forma confeccionou-se uma 'régua medidora de limões' (figura 2), com uma medida máxima $(0,65 \mathrm{~cm})$, onde o limão deveria passar, e uma medida mínima $(0,60)$, onde o limão não deveria passar na hora da compra

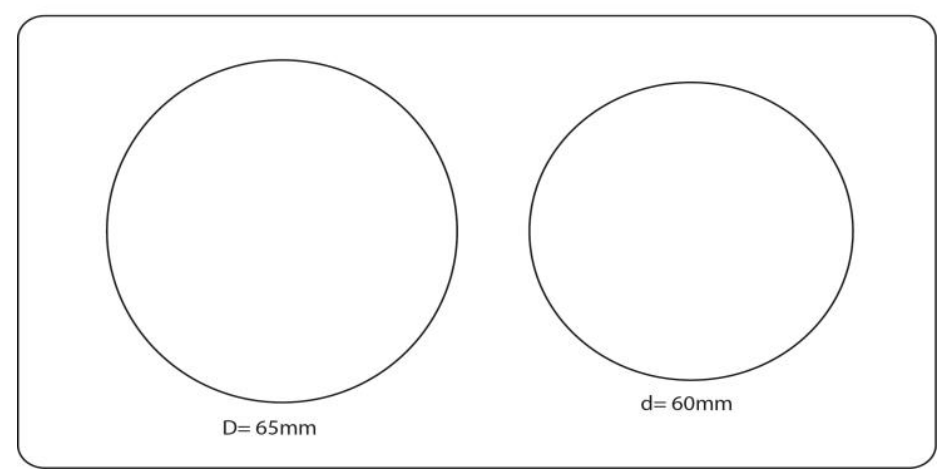

Figura 2 - Régua medidora de limões (elaborado pelo autor). 
Levando em conta que a importância de registrar-se a percepção dos sujeitos viuse que uma forma eficiente de conseguir o registro das impressões obtidas ao longo da interação e uso, seria filmar a coleta de dados. Para isso utilizou-se uma Câmera de Vídeo Digital Sony, modelo DCR - DVD 408 Handycam. Além disso, as gravações obtidas possibilitaram saber o tempo gasto para realização da tarefa.

Além disso, sendo a eficiência um dos resultados desejados por este projeto, utilizou-se para pesar os limões antes e depois de espremidos, uma Balança Eletrônica Filizola, modelo MF - 3/1, com peso máximo de 3 Quilogramas e Mínimo de 10 gramas.

\subsection{Protocolos}

Para melhor seleção e caracterização da amostra foram utilizados Protocolos de Identificação. Assim também, para melhor expressar os objetivos do estudo e as implicações éticas de participação dos sujeitos no teste, houve o uso do TCLE - Termo de Consentimento Livre e Esclarecido (atendendo a "Norma ERG-BR 1002, do código de Deontologia do Ergonomista Certificado" (ABERGO, 2003); e a resolução 196/96 CNS). Além disto, este estudo foi aprovado pelo CEP-USC (Processo 001/11).

Para a coleta de dados através do uso simulado dos objetos de estudo, utilizou-se protocolo de registros, que permitia o registro da avaliação feita após o uso dos espremedores acerca da 'Dificuldade' percebida em relação a cada um dos espremedores já usados, além de registro do tempo e do aproveitamento.

\subsection{Coleta}

As abordagens deste estudo foram realizadas no Laboratório de Ergonomia e Interfaces, na Unesp de Bauru.

Assim, os sujeitos, após preencherem os Protocólos de Idenfificação e o TCLE, realizavam o uso dos espremedores (em ordem randomizada) (figura 3), realizando a tarefa de espremer um limão inteiro em cada espremedor.

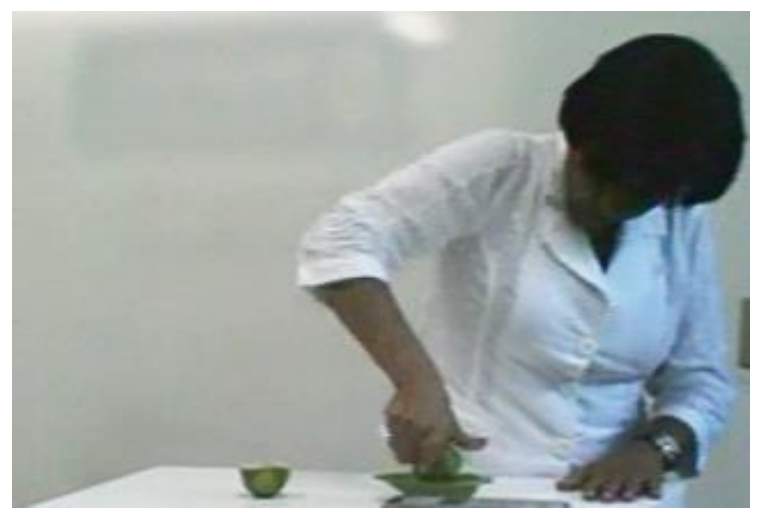

Figura 3 - Imagens da coleta de dados (elaborado pelo autor).

Destacando-se que, para obtenção do aproveitamento do limão em cada espremedor, os limões foram pesados antes e depois de serem espremidos.

Com base no que afirma Kotler e Keller (2006), a "satisfação é o sentimento de prazer ou de desapontamento resultante da comparação entre o desempenho (ou resultado) percebido de um produto e as expectativa do comprador", optou-se por questionar a 'Dificuldade percebida'. Dessa forma, finalizava-se a coleta pedindo que 
os sujeitos posicionassem os espremedores - um a um - em uma escala gráfica de 'Dificuldade'(figura 4) colocada sobre uma mesa, onde a menor dificuldade correspondia ao menor valor (um) e a maior dificuldade ao maior valor (cinco).

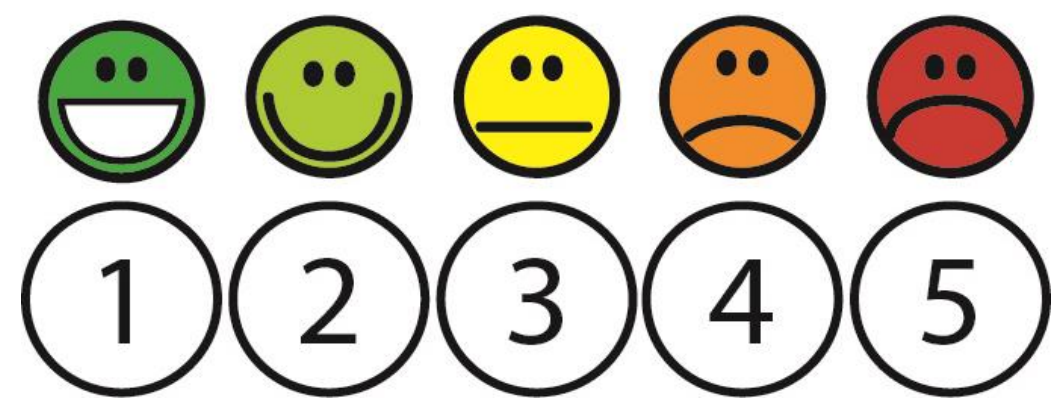

Figura 4 - Escala de Dificuldade percebida (elaborado pelo autor).

\subsection{Análise de dados}

Os dados coletados foram organizados em planilhas e submetidos à análise estatística com o teste não paramétrico de Wilcoxon, objetivando identificar diferenças significativas $(P \leq 0,05)$ entre os diferentes espremedores para as variáveis 'dificuldade', 'tempo' e 'aproveitamento.

\section{Resultados e Discussões}

\subsection{Satisfação}

\subsubsection{Dificuldade percebida}

As médias e respectivos desvio-padrão da 'dificuldade percebida' (escala de 1 a 5), para os cinco espremedores de frutas, à saber " $A$ ", " $B$ ", " $C$ ", " $D$ " e "E", estão apresentadas na figura 5 , junto aos valores de significância.

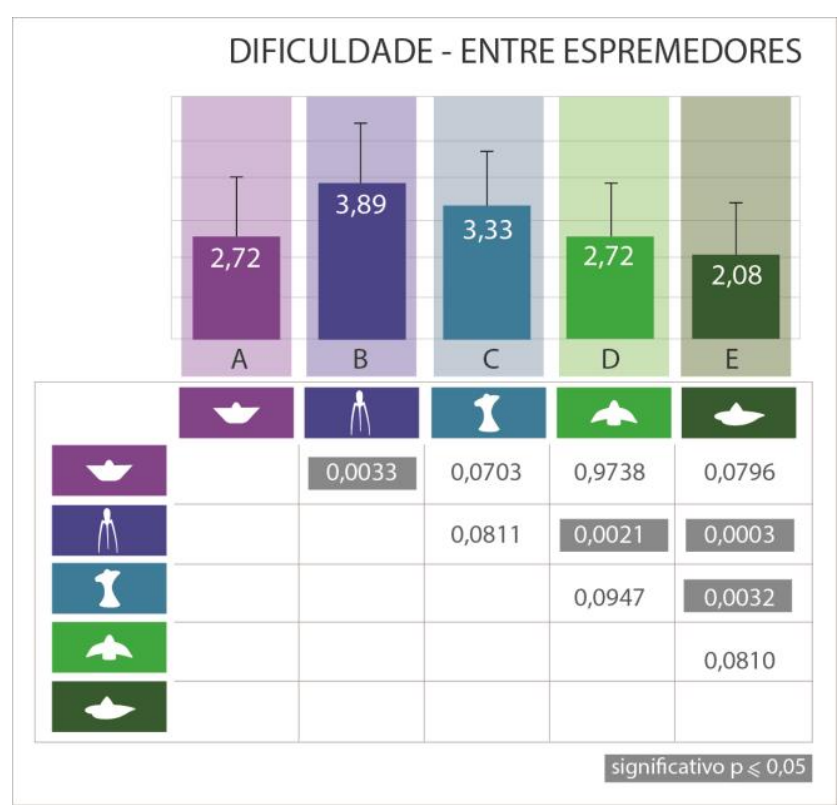

Figura 5 - Médias de Dificuldade de realização da tarefa na comparação entre espremedores e valores de " $p$ " da análise comparativa (elaborado pelo autor com base em pesquisa realizada).

Ao se observar apenas as médias de dificuldade relatadas pelos sujeitos, nota-se que o espremedor $B$ se destacou como o mais difícil, seguido por C. Contrariamente, A, D e E apresentaram as menores médias e se apresentaram como os espremedores em que houve as menores dificuldades relatadas. 
No entanto, houve diferença significativa apenas entre $B$ em relação a $A, D$ e $E$; e entre $\mathrm{C}$ e $\mathrm{E}$.

\subsection{Eficiência}

\subsubsection{Tempo}

Com relação ao critério 'tempo', as médias e respectivos desvio-padrão do Tempo/Eficiência (em segundos) exigidos para a realização da atividade, para os cinco espremedores de frutas: “ $A$ ", " $B$ ", " $C$ ", " $D$ " e “E”, estão apresentadas na figura 6, juntamente com os valores de significância.

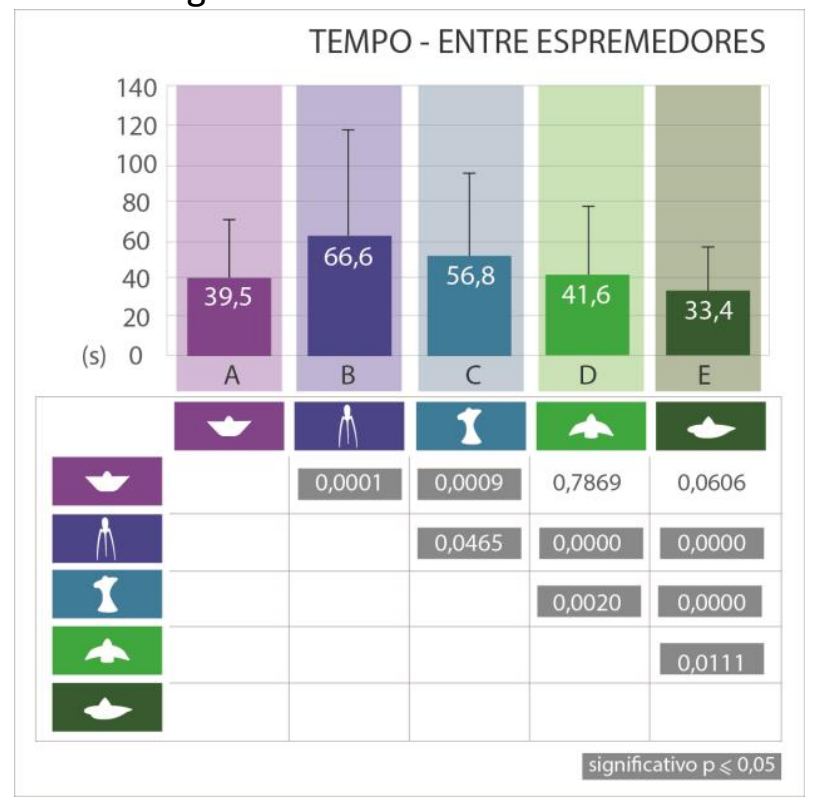

Figura 6 - Médias de Tempo de realização da tarefa na comparação entre espremedores e valores de "p" da análise comparativa (elaborado pelo autor com base em pesquisa realizada).

Assim, pode-se notar que B e $C$ se diferenciaram significativamente $(p \leq 0,05)$ dos demais como aqueles nos quais se realizaram as tarefas em maior tempo, o que pode estar relacionado à falta de familiaridade com a forma do objeto, uma vez que os espremedores B e C são os mais diferenciados.

Valendo destacar, que $D$ e $E$ se diferenciaram de maneira significativa dos demais e entre si, com exceção a A. No entanto essa diferenciação ocorreu no sentido oposto, ou seja, se destacaram como espremedores nos quais se realizaram as tarefas mais rapidamente.

\subsubsection{Aproveitamento}

Com relação ao critério 'Aproveitamento', as médias e respectivo desvio-padrão do nível de Eficiência (em \%), para os cinco espremedores de frutas: " $A$ ", " $B$ ", " $C$ ", " $D$ " e "E", estão apresentadas na figura 7, juntamente com os valores de significância. 


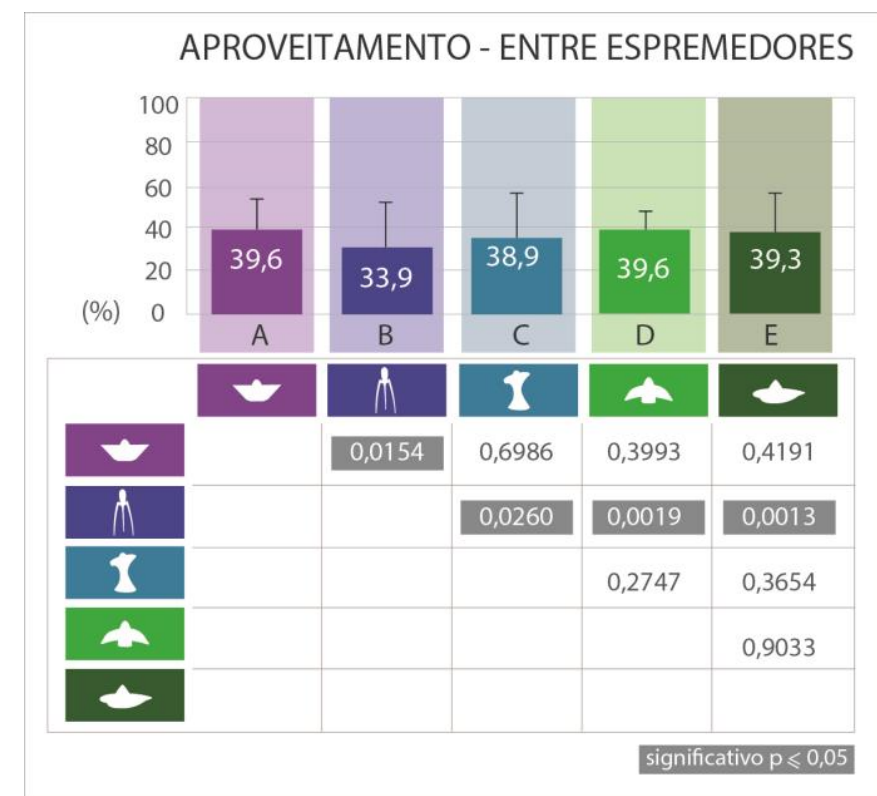

Figura 7 - Médias de Aproveitamento na comparação entre espremedores e valores de " $p$ " da análise comparativa (elaborado pelo autor com base em pesquisa realizada).

Dos quais se pode afirmar que o espremedor B é significativamente $(p \leq 0,05)$ o menos eficiente em relação aos demais, que apresentaram médias de eficiência muito próximas.

\section{CONCLUSÃO}

Critérios de usabilidade tem sido amplamente utilizados para avaliação da interface homem-computador, no entanto seu escopo tem se expandido para produtos de uso diário, o que pode conferir uma maior confiabilidade no que diz respeito a interface do homem com toda interface tecnológica disponível. Embora haja afirmações de que as questões que permeiam esta interface já estejam estabelecidas, deve-se notar que num mercado com tão grande oferta de produtos, muitos dos quais de diferentes formas e com uma mesma função, há a necessidade de compreender a influência dessas diferenças no momento do uso.

É fato que o fator que diferencia os objetos utilizados neste estudo vão além da forma, se relacionando também a diferenças estéticas e de significação.

Os resultados acima expostos demonstram que o espremedor $\mathrm{B}$ - certamente $\mathrm{O}$ objeto de maior valor estético e simbólico reconhecido - foi o ultimo classificado para todas as variáveis (aproveitamento, tempo e dificuldade), opondo-se significativamente ao espremedor E para as variáveis 'tempo' e 'dificuldade', e ao D quanto ao 'aproveitamento'.

Ao que se pode afirmar que os espremedores $D$ e $E$ se destacaram nos critérios de 'eficiência' e o espremedor E se destacou quanto a 'Satisfação' em relação ao espremedor $\mathrm{B}$.

Ao que se pode discutir a importância da expectativa dos sujeitos quanto aos produtos, uma vez que, sendo um objeto ícone de design e que pode ter gerado uma expectativa alta, o espremedor $B$ foi o pior relacionado quanto a 'dificuldade percebida'. De forma contrária, mas neste mesmo contexto, o espremedor $E$, de forma simples e tamanho reduzido, provavelmente gerou uma menor expectativa e por ter proporcionado uma interface agradável, uma melhor percepção. 


\section{REFERÊNCIAS}

ABNT - Associação Brasileira de Normas Técnicas. Requisitos Ergonômicos para Trabalho de Escritórios com Computadores. 2002. NBR 9241 Parte 11 - Orientações sobre Usabilidade. Disponível na internet por http em: <www.inf.ufsc.br/ cybis/pg2003/iso9241-11F2.pdf > . Acesso em 15 de março de 2012.

ALESSI. Juicy Salif. Disponível na internet por http em: <www.alessi.com>. Acessado em: 10 de fevereiro de 2013.

CHAMMAS, A. S.; MORAES, A. Ergonomia Informacional: Fundamentos e Aplicação. In: Encuentro Latinoamericano de Diseño, 2007, Palermo. Encuentro Latinoamericano de Diseño, 2007.

CYBIS, W. et al. Ergonomia e Usabilidade: Conhecimentos, Métodos e Aplicações(2aㅡd.). São Paulo: Novatec, 2010.

HAN, S. H. et al. Usability of electronic consumer products. International Journal of Industrial Ergonomics, 28,2001. p. 143-151.

IIDA, I. Ergonomia: Projeto e Produção (2a Ed.). São Paulo: Edgard Blücher, 2005.

IKKO. Corisco. Disponível na internet por http em: <www.ikko.com.br/index.php>. Acesso em 10 de fevereiro de 2013.

KOZIOL.Ahoi. Disponível na internet por http em: <www.koziol.de/en/unternehmen/Unternehmen-koziol. .php?navid=1243194933573> .

Acesso em 10 de fevereiro de 2013.

LLOYD, P. SNELDERS, D. Starck What was Philippe thinking of? In: P. Lloyd and H. Christiaans (eds), Designing in Context (Delft: Delft University Press), 241-257, 2001.

MORAES, A. D. Ergonomia e usabilidade de produtos, programas, informação: área de concentração, linhas de pesquisa, projetos de pesquisa, ideias, realizações, produção e competências. In: MORAES, A. D.; FRISONI, B. C. Ergodesign: produtos e processos. Rio de Janeiro: $2 A B, 2001$. p. 9-50.

MORAES A. de; FRISONI B.C. Ergodesign: uma associação. In: MORAES A. de; FRISONI, B.C. Ergodesign: produtos e processos. Rio de Janeiro: 2AB, 2001, pp. 195-206.

PLASUTIL. Disponível na internet por http em: $<$ www.plasutil.com.br/plasutil/pt/index.php. Acessado em: 10 de fevereiro de 2013 $>$.

QUALY. Disponível na internet por http em: <www.newarriva.com/qualy/main.html>. Acesso em 10 de fevereiro de 2013.

RUSSO, B.; MORAES, A. The Lack of Usability in Design Icons. In: Designing Pleasurable Products 2003, Pittsburgh. Proceeding of DPPI'03 - Pittsburgh - Pennsylvannia - USA, 2003. 
SANTA ROSA, J. G.; MORAES, A. D. Design participativo, técnicas para inclusão de usuários no processo de ergodesign de interfaces (1 1 Ed). Rio de Janeiro: Rio Books, 2012a.

SANTA ROSA, J. G.; MORAES, A. D. Avaliação e projeto no design de interfaces (1a Ed.). Rio de Janeiro: $2 A B, 2012 b$.

SILVA, C. M.A.; OKIMOTO, M.L.O. Considerando a intuição no uso de produtos: o caso juicy Salif. In: 11을 Ergodesign/11은, 2011, Manaus. Anais do 11을 Ergodesign/11으 USHIC. Manaus : UFAM, 2011. 